\title{
The relationship between resilience and loneliness elucidated by a Danish version of the resilience scale for adults
}

\author{
Ida Skytte Jakobsen ${ }^{1}$, Lykke Mie Riis Madsen ${ }^{1}$, Martin Mau ${ }^{1,4,5^{*}}$ (D), Odin Hjemdal ${ }^{2}$ and Oddgeir Friborg ${ }^{3}$
}

\begin{abstract}
Background: Research on the relationship between resilience and loneliness is sparse. The construct of resilience has been conceptualized in multiple ways, including the measurement of resilience. The Resilience Scale for Adults (RSA) is a measure of protective factors. The present study examined whether resiliency moderates any negative relationship between loneliness and mental health and additionally examined the psychometric properties of the Danish translation of the RSA.

Methods: A Danish sample ( $N=422)$ completed the UCLA Loneliness Scale, Hopkins Symptom Check List-25 (HSCL25), the Sense of Coherence (SOC-13), and the RSA, Resilience Scale for Adults.

Results: The measure of loneliness correlated significantly and negatively with most facets of the RSA, except the subscales of family cohesion and structured style. The strongest correlation was the negative one between loneliness and SOC. The results indicated that people feeling lonely also experience their life as less meaningful.

Conclusion: The study supports the existing six-factor structure of the Resilience Scale for Adults (RSA) in a Danish sample. The results indicate that all facets of resiliency were negatively related to loneliness. Also, the facets of perception of self and family coherence could explain a substantial amount of the variance associated with symptoms of depression in relation to loneliness.
\end{abstract}

Keywords: Loneliness, Resiliency, Protective factors

\section{Background}

The social nature of human beings manifests itself as a basic need to belong [1], which, if not satisfied, may induce experiences of loneliness. To most people, loneliness is an aversive state of mind prompted by a discrepancy between the desired and actual quality of one's interpersonal relationships [2]. Loneliness is subjective or individual, as objectively socially connected people may still feel lonely [3]. Numerous studies focusing on different age groups (for reviews see $[1,4,5]$ ) report an

\footnotetext{
*Correspondence: mama@ucl.dk

1 Health, Social Work and Welfare Research, UCL University College,

Odense, Denmark

Full list of author information is available at the end of the article
}

association between loneliness and different negative affective conditions. Among young adults, this raises awareness of loneliness as a risk factor for later negative affective problems [6], such as depression or anxiety [3], and eventually suicidal ideation as well as parasuicide [4]. Moreover, long-lasting loneliness may trigger additional problems such as stigmatization and social isolation [3] and may affect an individual's cognition and behavior towards their social environment in a way that maintains feelings of isolation [7].

An interesting phenomenon is that not all chronically lonely people develop depression or anxiety, or develop other functional problems related to maladaptation. Some come to terms with their way of existence and may have adapted reasonably well. The present study 
examined this perspective by including variables that are protective of mental health.

Several concepts may be helpful in this regard. One is resilience as this research area delineates a range of factors that may promote adaptation and protect health despite exposure to adversity or hardships [8]. One may thus assume that well-adjusted lonely people may have more or better mental health protective factors available in their life. A relevant instrument in this regard is the Resilience Scale for Adults (RSA) [9], which the present study used.

The construct Sense of Coherence, as conceptualized by Antonovsky [10], is strongly related to positive mental health and adaptation in general and is a concept, which provides a cross-culturally validated comprehensive measure of positive mental health. According to Antonovsky [11], it represents" a generalized orientation toward the world which perceives it, on a continuum, as comprehensible, manageable and meaningful". An individual with a high SOC has the capability to find meaning and purpose in life despite adversity. As such, it represents a general adaptation measure of stress. Moreover, high SOC persons have a positive expectation that new situations or challenges by conceiving them as comprehensible and manageable. The operationalization of the construct into the SOC-13 measure has been translated to more than 40 languages showing strong crossculturally validity [12]. Given the considerably strong relationship with positive mental health as well as stress dampening effect of high SOC, we included the SOC-13 measure.

As a Danish version of the RSA is not yet tested or validated, the second aim of this study was to validate the original RSA. By added a measure of SOC to the study, we could learn both more about the association between SOC and RSA, and compare the RSA with a well-validated instrument.

\section{Resilience}

The construct of resilience has been conceptualized in multiple ways, including the measurement of resilience [13]. Traditionally, resilience has been conceptualized as a certain outcome, e.g., 'normal development under difficult conditions' [14]. Such definitions may cause discussions about what constitutes 'normal development'. Measurement of precursors of such end states may instead be more fruitful by providing knowledge about factors that promote favorable outcomes, which should be more valuable within a preventive or a clinical health perspective. The measurement of protective factors, as representative of this approach, may be preferable.

A review of existing self-rating resilience measures, [15] revealed no gold standard of measurement; yet, the RSA by [9] was positively rated. The RSA is a selfrating resilience measure that assesses protective factors across three broad classes: individual or personal, family, and social resources. These extra-individual factors as part of the RSA makes it well suited to examine loneliness as a social construct. The RSA was originally developed in Norway by [9]. Numerous later studies on Norwegian samples support its reliability and validity [16-22]. The cross-cultural validity is also accumulating, showing adequate support in for example in Peru [23], Pakistan [24], India [25, 26], Iran, [27], Frenchspeaking Belgian [28], Brazil [29], in Lithuania [30] and in English with a sample from Australia [24]. An investigation of the psychometric properties of the RSA in a Danish sample has not yet been made, which was another impetus of the present study.

\section{Loneliness, resilience, and sense of coherence}

Research on relationships between resilience and loneliness is so far sparse. Some loneliness studies on the elderly [31-34], young homeless people [35, 36], and on students [34], showing that resilience may protect and even mediate relationships between loneliness and health-related outcomes. We, therefore, expect similar favorable effects of adding the RSA to the current study of relationships between loneliness and mental health.

The Sense of coherence scale comprises three components that are combined in a single index: comprehensibility, manageability, and meaningfulness, which indicates a person's global approach towards challenges, stressors, or adversities in their life. Antonovsky [10] argues that a person with a high SOC will more quickly analyze, understand, spot solutions, identify ways of appropriate coping, as well as finding meaning in dealing successfully with the implied challenges, which ultimately, improves that person's general adaptability. It has been considered a part of protective factors that contribute to resilience and is negatively associated with loneliness $[37,38]$.

The present study examined the psychometric properties of the Danish translation of the RSA. The test score reliability was expected to be adequate. We also expected the RSA to correlate in expected directions variables related to loneliness and mental health (anxiety and depression), thus supporting convergent validity. Moreover, since the RSA is presumed to assess protective factors that in theory should dampen any negative health effects of risk variables, such as loneliness, we additionally expected the RSA to moderate (or dampen) any negative relationship between loneliness and mental health. 


\section{Method}

\section{Subjects}

Participants were recruited from the UCL University College in Odense, Denmark. Data were collected via an online survey, which was distributed to 575 university students. The response rate was $73.4 \%$ as 422 students completed the survey (136 male-32\%, and 284 female $-68 \%)$. The sample consisted of first-year students studying pedagogics (36\%), nursing (16\%), biomedical laboratory science (12\%), teaching (3\%), or the full-degree business academy program (33\%). Their age ranged from 19 to 56 years $(M=25.4, S D=6.18)$ with females 25.4 years in average $(S D=6.48)$ and males being 25.6 years $(S D=5.57)$.

\section{Procedures}

The initial contact was to the headmaster at each department, explaining the aim of the study and the procedure. Hereafter, the students could access the questionnaire through their online student platform. All students were explained the purpose and confidentiality of the study, and that participation was voluntary. Data was collected from August 2018 to December 2018.

\section{Demographics}

Information about the students' gender, age, and marital status were gathered. Race, ethnicity, and income were not covered.

\section{Instruments UCLA loneliness scale}

The Three-Item Loneliness Scale (T-ILS) is a short version adapted from the standard measure of loneliness, the Revised UCLA Loneliness Scale. The short version of the scale has demonstrated concurrent validity and good internal consistency [39]. The T-ILS includes three items: "1) How often do you feel left out?", “2) How often do you feel that you lack companionship?", and "3) How often do you feel isolated from others?" Responses are scored on a three-point scale ranging between 1-"hardly ever", 2-"some of the time" and 3-"often". A principal component analysis of this scale in the present study yielded an eigenvalue of 2.27 $\left(R^{2}=76 \%\right)$, clearly supporting the adequacy of creating a general loneliness index as the average of these three items (higher scores indicating more loneliness).

\section{Resilience scale for adults (RSA)}

The RSA [9] is a 33 item self-report scale developed for measuring protective resilience factors among adults. It assesses an individual's available resilience resources across an intrapersonal domain (perception of self, perception of future, social competence and having a structured style), and across a focal interpersonal domain (i.e., cohesion in the family) and a more distal interpersonal domain (i.e., extra-family social resources). The instrument uses a seven-point semantic differential scale in which each item has a positive and a negative attribute at each end of the scale [17]. Half of the items are reversely scored to reduce acquiescencebiases. In the questionnaire, the items constructing the five subscales are mixed. An example of an item is 'My family is characterized by': where one end of the scale goes from Healthy cohesion to Disconnection.

Higher scores indicate higher levels of protective resilience factors with an adequate measurement reliability (alpha ranging between $\sim .70$ and $\sim 85[40,41]$;. The construct and cross-cultural validity of the RSA is well documented, and it is a recommended resilience scale [15].

\section{The Hopkins symptom check List-25 (HSCL-25)}

We used a Danish version of the instrument HSCL-25 [42], a self-report instrument that measures psychopathological symptoms (i.e. depression, anxiety, and total distress). It contains 13 depression items, 10 anxiety items, and 2 somatic items. All items have a Likert scale with four categories ("Not at all," "A little," "Quite a bit," "Extremely,"), where higher scores indicate higher levels of psychiatric or affective symptoms. HSCL-25 is one of the most widely used screening instruments for psychopathologic symptoms [43] with reports of good internal consistency (standardized Cronbach's $\alpha$ ) generally, $\alpha>.90$ for the total score, and $\alpha>.80$ for anxiety and depression [44]. It has been found to be a valid screening instrument in both Western and non-Western populations [45-47] with some exceptions [48].

\section{Sense of coherence (SOC-13)}

The SOC-13 is a brief version of the SOC-29 self-report questionnaire [49]. The instrument measures Sense of Coherence, which has been associated with resilience, thus indicating that it is a factor in determining one's ability to cope with harsh events [50]. In addition, the instrument has in former studies demonstrate significant positive correlations with RSA [16].

SOC-13 measures psychological constructs that comprise Sense of Coherence, namely: comprehensibility (cognitive), manageability (instrumental/behavioral), and meaningfulness (motivational) [51]. We have used the adapted SOC-13, which has been translated into Danish. The scale is introduced, as "Here is a series of questions relating to various aspects of our lives". Each question has five possible answers [52]. Higher scores indicate 
higher levels of SOC and thus a higher level of individual adjustment.

The Sense of Coherence (SOC-13) a reliable instrument for measuring the individual's potential adjustment and rehabilitation to stressful life experiences [51, 53]. Exemplar items are: 1) "Do you have the feeling that you are in an unfamiliar situation and don't know what to do? (Comprehension), 2) "How often do you have feelings that you're not sure you can keep under control?" (Manageability), and 3)"How often do you have the feeling that there's little meaning in the things you do in your daily life?" (Meaningfulness).

\section{Statistics}

SPSS 25 and Mplus 7.4 [54] was used for all inferential and confirmatory factor analyses (CFA), respectively.

In Mplus, the robust ML (maximum likelihood) estimator was used to adequately adjust for non-normal item score distributions. As the chi-square absolute fit measure is sensitive to large sample sizes [55], the root-mean-square error of approximation (RMSEA) and the non-normed fit index (NNFI) were additionally consulted. RMSEA values $<.06$ are preferable [56], while values for NNFI should minimally pass $>.90$ [57] or preferably $>.95$ [58]. Standardized root mean residuals should ideally be less than $<.08$, which represents the average size of the residual item correlations after fitting the factor model.

The regression analyses were bootstrapped using 1000 resamplings in order to produce confidence intervals and significance tests less biased by non-normally distributed scores, as was the case for the HSCL depression and anxiety scores.

Beta coefficients with $p$-value $<.05$ was deemed as statistically significant. The regression models were conducted in steps. All continuous variables were grand centered, and dichotomous variables were dummy coded (0 versus 1$)$. In the first step, we entered loneliness, thus yielding its crude or unadjusted relationship with anxiety or depressive symptoms. In the second and third step, the resilience variables and the SOC measure was added, respectively. In the final block, their interaction terms were additionally included (loneliness $\times$ RSA or loneliness $\times$ SOC) along with a final adjustment by including the covariates (e.g., age, gender, and education). The performance of these models was gauged with the adjusted R-square index (range 0-1) indicating the degree of variance explained by the model.

\section{Results}

\section{Descriptive statistics}

The score range, means (or proportions), standard deviations of all variables, as well as the reliability coefficients of the measurement scales, are presented in Table 1. The interrelationships between these variables are given as Pearson correlation coefficients. The psychometric properties of the RSA, the HSCL-25, and SOC-13 were adequate.

The reliability coefficients for the subscales of the RSA were acceptable as the Cronbach's alphas varied in the range between $.81-.87$ for the subscales planned future, family cohesion, social resources, personal competence, and social competence (in falling order). The subscale "structured style" was however in the sub-optimal range $(\alpha=.66)$.

Loneliness was in general strongly associated with higher levels of anxiety and depressive symptoms. Moreover, loneliness correlated significantly and negatively with most facets of the RSA, except for the subscales of family cohesion and structured style. The strongest correlation was the negative one between loneliness and SOC, thus indicating that people feeling lonely also experience their life as less meaningful, comprehensible, and manageable. Moreover, the RSA and the SOC were strongly positively correlated, as has been previously reported [19].

\section{Confirmatory factor analysis}

The fit of the six-factor RSA measurement model was examined in a confirmatory factor analysis, which confirmed adequate fit in terms of a low degree of model misspecification $\quad\left(\mathrm{RMSEA}=.052, \quad C I_{.95} \quad .048-.056\right.$; SRMR $=.066$ ), whereas the relative fit was mediocre $(\mathrm{CFI}=.898, \mathrm{TLI}=.888)$. The modification indices indicated that one item originally belonging to the social resource factor (becoming informed if a family member experiences a crisis) loaded strongly on the family cohesion factor $(\lambda=.65)$. Switching this item to the family cohesion factor, which is reasonable given the overlap in semantic meaning, improved absolute fit (RMSEA $=.049$, $\left.\mathrm{CI}_{.95} .045-.054, \mathrm{SRMR}=.063\right)$ and relative fit $(\mathrm{CFI}=.909$, $\mathrm{TLI}=.900)$. The standardized factor loadings are given in Table 2.

\section{The relationship between loneliness and mental health, and the contributing role of RSA and SOC as protective factors (or moderators)}

Loneliness was regressed upon depression (Table 3) and anxiety (Table 4) and stratified to retain genderspecific effects. As a single variable (crude effect), loneliness had the highest association with depressive symptoms in men $\left(R^{2}=41 \%\right)$, thereafter depressive symptoms in women $\left(R^{2}=38 \%\right)$, and then anxiety in both men and women $\left(R^{2}=20\right.$ and $21 \%$, respectively). Adding resilience to the equation in the second block explained substantially more of the variance in mental 
Table 1 Pearson correlations coefficients, Cronbach's alphas and descriptive statistics for the measurement variables $(N=422)$

\begin{tabular}{|c|c|c|c|c|c|c|c|c|c|c|c|c|c|c|c|}
\hline & \multicolumn{15}{|c|}{ Variables } \\
\hline & 1 & 2 & 3 & 4 & 5 & 6 & 7 & 8 & 9 & 10 & 11 & 12 & 13 & 14 & 15 \\
\hline \multicolumn{16}{|l|}{ Outcome } \\
\hline $1 \mathrm{HSCL}$ anx & .86 & & & & & & & & & & & & & & \\
\hline $2 \mathrm{HSCL}$ depr & .66 & .90 & & & & & & & & & & & & & \\
\hline \multicolumn{16}{|l|}{ Risk variable } \\
\hline 3 Loneliness & .46 & .62 & .84 & & & & & & & & & & & & \\
\hline \multicolumn{16}{|l|}{ Protection } \\
\hline 4 RSA pc & -.58 & -.66 & -.51 & .85 & & & & & & & & & & & \\
\hline 5 RSA fut & -.49 & -.67 & -.51 & .68 & .88 & & & & & & & & & & \\
\hline 6 RSA sc & -.34 & -.50 & -.56 & .49 & .51 & .81 & & & & & & & & & \\
\hline $7 \mathrm{RSA}$ fC & -.34 & -.46 & -.38 & .35 & .42 & .43 & .87 & & & & & & & & \\
\hline $8 \mathrm{RSA} \mathrm{sr}$ & -.41 & -.57 & -.57 & .48 & .54 & .56 & .68 & .87 & & & & & & & \\
\hline 9 RSA sS & -.15 & -.35 & -.20 & .30 & .45 & .19 & .31 & .29 & .66 & & & & & & \\
\hline $10 \mathrm{SOC}$ & -.63 & -.77 & -.67 & .72 & .68 & .52 & .49 & .61 & .40 & .90 & & & & & \\
\hline \multicolumn{16}{|l|}{ Covariates } \\
\hline $11 \mathrm{Age}$ & -.10 & -.04 & -.04 & .23 & .09 & .04 & -.07 & -.03 & .12 & .10 & & & & & \\
\hline 12 Marital stat. & .12 & .22 & .19 & -.20 & -.18 & -.09 & -.13 & -.15 & -.22 & -.24 & -.27 & & & & \\
\hline 13 Children & .08 & .11 & .07 & -.24 & -.17 & -.09 & -.02 & -.03 & -.19 & -.18 & -.69 & .39 & & & \\
\hline 14 Pets & -.03 & -.04 & -.11 & .02 & .05 & .06 & .03 & .06 & -.05 & .05 & -.19 & .15 & .18 & & \\
\hline 15 Sports & .05 & .14 & .17 & -.12 & -.18 & -.24 & -.14 & -.13 & -.23 & -.16 & -.03 & .00 & .00 & -.09 & \\
\hline \multicolumn{16}{|l|}{ Descriptive data } \\
\hline Range & $1-4$ & $1-4$ & $1-3$ & $1-7$ & $1-7$ & $1-7$ & $1-7$ & $1-7$ & $1-7$ & $1-5$ & $19-56$ & $0-1$ & $0-1$ & $0-1$ & $0-1$ \\
\hline M or $\%$ & 1.51 & 1.52 & 1.65 & 4.56 & 5.18 & 4.85 & 5.25 & 5.89 & 4.71 & 3.40 & 25.44 & .61 & .18 & .29 & .64 \\
\hline SD & .47 & .51 & .68 & 1.32 & 1.39 & 1.23 & 1.28 & 1.03 & 1.26 & 0.66 & 6.18 & .49 & .39 & .46 & .48 \\
\hline
\end{tabular}

Correlation coefficients above $x x x$ and $x x x$ are significant at the 0.05 and 0.01 . Cronbach's Alpha of the measurement scales are presented in the diagonal as bold text. $\mathrm{RSA} \mathrm{pc/fut} / \mathrm{sc} / \mathrm{fc} / \mathrm{sr} / \mathrm{ss}=$ personal competence / planned future / social competence / family cohesion / social resources / structured style

health, thus validating the Danish version of the RSA as a significant contributor in explaining mental health. Adding SOC in the third block, explained a substantial extra amount of the variance in the HSCL, as expected.

In the final block, RSA and SOC were added as moderators of the relationship between loneliness and HSCL in order to examine if these two respective was associated with an extra layer of protection in addition to their compensatory main effects. The RSA contributed significantly as moderators of depressive symptoms in men (notably, the subscales of perception of self and family coherence) and anxiety symptoms in men (RSA perception of self). Similar protective effects against depressive symptoms were not observed in women, whereas SOC was associated with a protective role against depressive symptoms in women. These findings indicated that both RSA and SOC showed compensatory (main) and protective (moderator) effects. The latter effects were more pronounced for the RSA measure.

\section{Discussion}

The current study showed that loneliness was related to both anxiety and depression and that all facets of resiliency were negatively related to loneliness, where higher loneliness was associated with lower resiliency, indicating that young adults who show a high degree of resilience also tended to feel less lonely. The relation between levels of loneliness and resilience is particularly interesting as it has not previously been reported, but it also supports the construct validity of the RSA.

A possible explanation for the relation between levels of resilience and levels of loneliness is that resilience represents the presence of both intra- and interpersonal resources that improve the adaptation to a more lonely existence. Similarly, situational characteristics, such as having few social resources, shallow or non-existing interpersonal relationships, are hypothesized as a predisposing factor for developing loneliness [59].

Thus, higher scores on loneliness, indicating the absence of social resources, would thus be expected 
Table 2 Factor loadings of the resilience scale for adults following a confirmatory factor analysis $(N=422)$

\begin{tabular}{|c|c|c|c|c|c|c|}
\hline Items & $\begin{array}{l}\text { Personal } \\
\text { competence }\end{array}$ & Planned future & Social competence & Family cohesion & Social resources & $\begin{array}{l}\text { Structured } \\
\text { style }\end{array}$ \\
\hline \multicolumn{7}{|l|}{ Factor 1} \\
\hline RSA1 & .70 & & & & & \\
\hline RSA7 & .67 & & & & & \\
\hline RSA13 & .69 & & & & & \\
\hline RSA19 & .77 & & & & & \\
\hline RSA25 & .77 & & & & & \\
\hline RSA29 & .59 & & & & & \\
\hline \multicolumn{7}{|l|}{ Factor 2} \\
\hline RSA2 & & .78 & & & & \\
\hline RSA8 & & .83 & & & & \\
\hline RSA14 & & .81 & & & & \\
\hline RSA20 & & .80 & & & & \\
\hline \multicolumn{7}{|l|}{ Factor 3} \\
\hline RSA3 & & & .46 & & & \\
\hline RSA9 & & & .56 & & & \\
\hline RSA15 & & & .83 & & & \\
\hline RSA21 & & & .86 & & & \\
\hline RSA26 & & & .45 & & & \\
\hline RSA30 & & & .69 & & & \\
\hline \multicolumn{7}{|l|}{ Factor 4} \\
\hline RSA4 & & & & .61 & & \\
\hline RSA10 & & & & .83 & & \\
\hline RSA16 & & & & .75 & & \\
\hline RSA22 & & & & .77 & & \\
\hline RSA27 & & & & .73 & & \\
\hline RSA31 & & & & .67 & & \\
\hline \multicolumn{7}{|l|}{ Factor 5} \\
\hline RSA5 & & & & & .70 & \\
\hline RSA11 & & & & & .78 & \\
\hline RSA17 & & & & & .64 & \\
\hline RSA23 & & & & .63 & & \\
\hline RSA28 & & & & & .83 & \\
\hline RSA32 & & & & & .69 & \\
\hline RSA33 & & & & & .79 & \\
\hline \multicolumn{7}{|l|}{ Factor6 } \\
\hline RSA6 & & & & & & .44 \\
\hline RSA12 & & & & & & .32 \\
\hline RSA18 & & & & & & .75 \\
\hline RSA24 & & & & & & .74 \\
\hline
\end{tabular}

to be associated with lower scores related to social resources such as resilience. Social resources are thought to be essential in mental health as researchers highlight that healthy adaptation is a process $[8,15,60]$. More specifically, it can be defined as a transactional process where resilience is developed through the individuals' dynamic interaction with their environment. It may also be described as the individual's ability to navigate between available resources [61].

Based on the narrow definition and measurement of loneliness in the present study, we cannot ascertain to what extent lonely people have or use social resources despite observing a strong negative correlation between loneliness and social resources. According to the model 
Table 3 Multiple regression analyses with HSCL depression as the dependent variable $(N=420)$

\begin{tabular}{|c|c|c|c|c|c|c|c|c|c|c|c|c|}
\hline & \multirow[b]{2}{*}{$R-s q$} & \multicolumn{5}{|c|}{ Men $(n=136)$} & \multirow[b]{2}{*}{$R-s q$} & \multicolumn{5}{|c|}{ Women $(n=284)$} \\
\hline & & Crude & $\operatorname{Adj} 1$ & $\operatorname{Adj} 2$ & Adj 3 & $\mathrm{Cl} 95 \%$ & & Crude & Adj 1 & Adj 2 & Adj 3 & $\mathrm{Cl} 95 \%$ \\
\hline Risk variable & .406 & & & & & & .384 & & & & & \\
\hline Loneliness & & $.75^{\mathrm{a}}$ & $.36^{\mathrm{a}}$ & .14 & .13 & $-.08 \mid .32$ & & $.57^{\mathrm{a}}$ & $.23^{\mathrm{a}}$ & $.15^{\mathrm{b}}$ & $.11^{\mathrm{c}}$ & $.00 \mid .21$ \\
\hline Protection & .600 & & & & & & .617 & & & & & \\
\hline RSA pc & & & $-.26^{b}$ & -.12 & $-.17^{c}$ & $-.35 \mid .01$ & & & $-.29^{\mathrm{a}}$ & $-.16^{\mathrm{a}}$ & $-.19^{\mathrm{a}}$ & $-.29 \mid-.09$ \\
\hline RSA fut & & & $-.23^{b}$ & $-.16^{c}$ & -.14 & $-.30 \mid .05$ & & & $-.24^{\mathrm{a}}$ & $-.20^{b}$ & $-.17^{b}$ & $-.29 \mid-.03$ \\
\hline RSA SC & & & .10 & .02 & -.01 & $-.19 \mid .18$ & & & -.03 & -.01 & .00 & $-.09 \mid .08$ \\
\hline RSA fC & & & $-.19^{c}$ & -.08 & $-.18^{c}$ & $-.36 \mid-.02$ & & & -.06 & -.05 & -.06 & $-.19 \mid .06$ \\
\hline RSA sr & & & -.10 & -.11 & .06 & $-.18 \mid .32$ & & & -.06 & .00 & .04 & $-.12 \mid .18$ \\
\hline RSA SS & & & -.04 & .03 & .04 & $-.09 \mid .19$ & & & -.03 & .00 & -.03 & $-.12 \mid .06$ \\
\hline SOC & .661 & & & $-.47^{\mathrm{a}}$ & $-.38^{b}$ & $-.59 \mid-.17$ & 649 & & & $-.34^{\mathrm{a}}$ & $-.32^{\mathrm{a}}$ & $\begin{array}{r}-.44 \mid \\
-.20\end{array}$ \\
\hline Interactions & .712 & & & & & & .678 & & & & & \\
\hline Lonely $\times$ RSApc & & & & & $-.16^{c}$ & $-.30 \mid .02$ & & & & & & \\
\hline Lonely $\times$ RSAfc & & & & & $-.20^{b}$ & $-.34 \mid-.06$ & & & & & & \\
\hline Lonely $\times$ SOC & & & & & & & & & & & $-.17^{\mathrm{a}}$ & $\begin{array}{r}-.25 \mid \\
-.09\end{array}$ \\
\hline Covariates & .706 & & & & & & .685 & & & & & \\
\hline
\end{tabular}

${ }^{\mathrm{a}} p<.001,{ }^{\mathrm{b}} p<.01$ and ${ }^{\mathrm{c}} p<.05$. No. of resamplings = 1000. Covariates were: Age (yrs), marital status (single/cohabitation), children (no/yes), Education (teacher, nurse, biomechanics vs other), pets (no/yes), engage in sports (no/yes). RSA pc/fut/sc/fc/sr/ss = personal competence / planned future / social competence / family cohesion / social resources / structured style, SOC $=$ Sense of Coherence

Table 4 Multiple regression analyses with HSCL anxiety as the dependent variable $(N=420)$

\begin{tabular}{|c|c|c|c|c|c|c|c|c|c|c|c|c|}
\hline & & Men $(n$ & 136) & & & & & Wome & $n=284$ & & & \\
\hline & $R$-sq & Crude & Adj 1 & Adj 2 & Adj 3 & $\mathrm{Cl} 95 \%$ & $R$-sq & Crude & Adj 1 & Adj 2 & Adj 3 & Cl95\% \\
\hline Riskvariable & .195 & & & & & & .209 & & & & & \\
\hline Loneliness & & $.43^{\mathrm{a}}$ & .16 & -.08 & -.05 & $-.24 \mid .11$ & & $.46^{\mathrm{a}}$ & $.18^{c}$ & .09 & .09 & $-.05 \mid .23$ \\
\hline Protection & .382 & & & & & & .386 & & & & & \\
\hline RSA pc & & & $-.28^{\mathrm{a}}$ & -.14 & $-.16^{c}$ & $-.31 \mid-.01$ & & & $-.43^{\mathrm{a}}$ & $-.29^{a}$ & $-.27^{\mathrm{a}}$ & $\begin{array}{r}-.42 \mid \\
-.11\end{array}$ \\
\hline RSA fut & & & -.10 & -.02 & .01 & $-.13 \mid .15$ & & & -.14 & -.10 & -.12 & $-.32 \mid .08$ \\
\hline RSA SC & & & .12 & .04 & .04 & $-.1 \mid .18$ & & & .06 & .08 & .07 & $-.08 \mid .22$ \\
\hline RSA fC & & & $-.19^{b}$ & -.08 & -.13 & $-.26 \mid .00$ & & & -.06 & -.04 & -.05 & $-.19 \mid .10$ \\
\hline RSA sr & & & -.04 & -.04 & .06 & $-.16 \mid .28$ & & & -.08 & -.03 & -.02 & $-.22 \mid .17$ \\
\hline RSA SS & & & -.07 & .00 & -.02 & $-.12 \mid .08$ & & & $.15^{\mathrm{c}}$ & $.19^{c}$ & $.17^{c}$ & $.04 \mid .31$ \\
\hline SOC & .486 & & & $-.49^{a}$ & $-.49^{a}$ & $-.69 \mid-.30$ & .416 & & & $-.37^{a}$ & $-.38^{\mathrm{a}}$ & $\begin{array}{c}-.57 \mid \\
-.18\end{array}$ \\
\hline Interactions & .542 & & & & & & & & & & & \\
\hline Lonely $\times$ RSApc & & & & & $-.22^{b}$ & $-.37 \mid-.02$ & & & & & ns & \\
\hline Lonely $\times$ SOC & & & & & ns & & & & & & ns & \\
\hline Covariates & .519 & & & & & & .414 & & & & & \\
\hline
\end{tabular}

${ }^{a} p<.001,{ }^{b} p<.01$ and ${ }^{c} p<.05$. No. of resamplings $=1000$. Covariates were: Age (yrs), marital status (single/cohabitation), children (no/yes), Education (teacher, nurse, biomechanics vs other), pets (no/yes), engage in sports (no/yes). RSA pc/fut/sc/fc/sr/ss = personal competence / planned future / social competence / family cohesion / social resources / structured style, SOC $=$ Sense of Coherence

of loneliness on cognition [7], feelings of loneliness are maintained through the individual's interaction with his or her social environment. Feelings of loneliness change cognitive expectations that may reinforce maladaptive behavior, e.g., hesitance, submissiveness, or withdrawal related to perceptions of the social sphere as threatening 
that also shapes memories of social interactions as more negative as compared to non-lonely people [7].

Loneliness as a subjective experience is typically distinguished from e.g. social isolation, which describes social circumstances more objectively. Future studies into the association between loneliness and resiliency could therefore benefit from a multi-dimensional approach to the study of loneliness encompassing both subjective and objective dimensions [62].

Furthermore, this study illustrated, that loneliness was strongly associated with worse mental health, and in particular, depression. This association between loneliness and other mental health problems adds to an understanding of loneliness as a complex phenomenon [6] associated with a range of challenges. This finding has also been replicated elsewhere in the literature, where loneliness seems to correlate with other mental health problems in reciprocal relationships $[3,63,64]$.

However, this study showed that resilience, specifically the facets of perception of self and family coherence, could explain a substantial amount of the variance associated with symptoms of depression in relation to loneliness, and the facet of perception of self was associated with anxiety in relation to loneliness.

The measure of RSA and the SOC are positively correlated which indicates that they both measure individual resources. The design of the study makes it impossible to detect any causal relation between the two or a causal relation between loneliness and SOC. The study can only report on a negative correlation between SOC and UCLA, which we can discuss from a theoretical perspective. The negative correlation is indicating that people feeling lonely also experience their life as less meaningful, comprehensible, and manageable. The social nature of humans makes relationships and the sense of belongingness a core component of how creates meaning in our lives. A key channel for humans to make lives understandable and comprehensible is to discuss, engage, and interact with other humans. In his original work from 1979, Antonovsky [65] argued that life experiences shape the sense of coherence and that SOC is a stable entity around the age of 30 . Since then a number of studies have shown that interventions can influence SOC levels and interventions focusing on strengthening SOC make be an important element in the effort to combat loneliness [66]..

The psychometric properties of the Resilience Scale for Adults (RSA) were supported with support for the existing six-factor structure and good reliability in a Danish sample, which indicates that this Danish version may be interesting when exploring levels of resilience. Further, the study explored the construct validity of the RSA. Since this is the first study reporting on the validity of the RSA in a Danish population, it is noteworthy that the overall results (Table 1) indicate that the construct validity of the RSA is supported. The significant positive correlations with Sense of Coherence, which measures adaptation in general, supports the construct validity of the RSA. As previously reported $[9,19]$ the magnitude of the correlation between the SOC and the individual RSA factors vary, indicating that different RSA factors relate differently to SOC and do not overlap. The construct validity is further supported by the significant negative correlations with the Hopkins Symptom Check List and thus levels of anxiety and depressive symptoms.

\section{Limitations}

One limitation of the present study is the young age of the participants. In addition, all participants were university students and the majority were young women. This implies caution concerning generalization, as this sample is not representative of the general adult population in Denmark. Further validity studies of the RSA on more heterogeneous samples in terms of age and occupation may address this uncertainty. However, given the ever-growing base of studies confirming the validity of the RSA, we except it to generalize beyond this university sample.

A second limitation is that the study applied a crosssectional design, and therefore our hypotheses direction and causality between loneliness and possible protective factors needs to be examined in future studies. Especially studies using longitudinal designs with repeated measures that would allow more causally related inferences as well as the identification of various trajectories of lonely people related to their mental as well as somatic health.

Age was adjusted for in the current study and as the adjusted statistical effect of loneliness became rather small or non-significant after adding the other covariates, and in particular sense of coherence, any further nuanced analyses of age should be of minor importance. However, given that, loneliness is manifested differently among young and older adults, further studies are called for, in order to shed some light upon a more comprehensive understanding of the implication of age.

\section{Conclusion}

The current study showed that loneliness measured by the UCLA was negatively related to all facets of resiliency measured by the RSA. The psychometric properties of the RSA were supported in a Danish sample reproducing the original factor structure. As specific aspects of the RSA could explain a substantial part of the variance in anxiety and depressive symptoms associated with loneliness, resiliency may be an important concept to consider in the loneliness research. The need for additional 
research is especially evident in relation to interventions targeted loneliness among young people, as interventions aimed at reducing loneliness levels have showed only negligible effects [6].

As the concept of resiliency can inspire interventions targeted prevention or reduction of mental health problems [58], we encourage future studies to examine more closely how resiliency factors and resilience may moderate the association between mental health problems and loneliness.

\section{Abbreviations}

CFI: Comparative fit index; HSCL-25: The Hopkins Symptom Check List-25; ML: Maximum likelihood; NNFI: Non-normed fit index; RMSEA: Root-mean-square error of approximation; RSA: The Resilience Scale for Adults; SOC-13: The Sense of Coherence Scale; SRMR: Standardized root mean square residual; T-ILS: The Three-Item Loneliness Scale; TLI: Tucker-Lewis index.

\section{Acknowledgements}

None.

\section{Authors' contributions}

ISJ: theoretical background, statistical analysis, and implications, LMRM: theoretical background, data gathering. MM: theoretical background and implications. OH: statistical analysis and interpretation. OF: statistical analysis and interpretation. All authors read and approved the final manuscript.

\section{Funding}

This research did not receive any specific grant from funding agencies in the public, commercial, or not-for-profit sectors.

\section{Availability of data and materials}

The datasets used and analyzed during the current study are available from the corresponding author on reasonable request.

\section{Ethics approval and consent to participate}

This study was registered at the University College UCL legal services for use with the Danish Data Protection Agency. Ethics approval was not needed according to national regulations (see https://www.nvk.dk/forsker/naar-duanmelder/hvilke-projekter-skal-jeg-anmelde). Written informed consent was obtained before any gathering of data.

\section{Consent for publication}

Not applicable.

\section{Competing interests}

The authors declare that they have no competing interests.

\section{Author details}

${ }^{1}$ Health, Social Work and Welfare Research, UCL University College, Odense, Denmark. ${ }^{2}$ Department of Psychology, Norwegian University of Science and Technology, Trondheim, Norway. ${ }^{3}$ Department of Psychology, UiT The Arctic University of Norway, Tromsø, Norway. ${ }^{4}$ Department of Psychology, University of Southern Denmark, Odense, Denmark. ${ }^{5}$ Health Sciences Research Centre, UCL University College, Odense, Denmark.

Received: 14 May 2020 Accepted: 24 November 2020

Published online: 10 December 2020

\section{References}

1. Cacioppo JT, Patrick W. Loneliness: Human nature and the need for social connection. WW Norton \& Company; 2008.

2. Perlman D, Peplau LA. Toward a social psychology of loneliness. Pers Relat. 1981;3:31
3. Hawkley LC, Cacioppo JT. Loneliness matters: a theoretical and empirical review of consequences and mechanisms. Ann Behav Med. 2010:40(2):218-27.

4. Heinrich LM, Gullone E. The clinical significance of loneliness: a literature review. Clin Psychol Rev. 2006;26(6):695-718.

5. Jaremka LM, Andridge RR, Fagundes CP, Alfano CM, Povoski SP, Lipari AM, et al. Pain, depression, and fatigue: Ioneliness as a longitudinal risk factor. Health Psychol. 2014;33(9):948-57.

6. Cacioppo JT, Hawkley LC, Ernst JM, Burleson M, Berntson GG, Nouriani B, Spiegel D. Loneliness within a nomological net: an evolutionary perspective. J Res Pers. 2006:40:1054-85.

7. Cacioppo JT, Hawkley LC. Perceived social isolation and cognition. Trends Cogn Sci. 2009;13:447-54.

8. Luthar SS, Cicchetti D. The construct of resilience: implications for interventions and social policies. Dev Psychopathol. 2000;12(4):857-85.

9. Hjemdal $\mathrm{O}$, Friborg $\mathrm{O}$, Martinussen $\mathrm{M}$, Rosenvinge J. Preliminary results from the development and validation of a Norwegian scale for measuring adult resilience. J Norwegian Psychological Assoc. 2001;38(4):310-7.

10. Antonovsky A. The structure and properties of the sense of coherence scale. Soc Sci Med. 1993:36:725-33.

11. Antonovsky A. The salutogenic model as a theory to guide health promotion. Health Promot Int. 1996;11(1):11-8.

12. Eriksson M, Mittelmark MB. The sense of coherence and its measurement I: Mittelmark MB, Sagy S, Eriksson M, Bauer GF, Pelikan JM, Lindström B, Espnes GA. The handbook of salutogenesis. Cham: Springer; 2017.

13. Prince-Embury S. Translating resilience theory for assessment and application with children, adolescents, and adults:. p. 9-16. In: Conceptual issues. Resilience in children, adolescents, and adults. New York: Springer; 2013.

14. Fonagy $\mathrm{P}$, Steele $\mathrm{M}$, Steele $\mathrm{H}$, Higgitt A, Target M. The Emanuel miller memorial lecture 1992 the theory and practice of resilience. J Child Psychol Psychiatry. 1994;35(2):231-57.

15. Windle G, Bennett KM, Noyes J. A methodological review of resilience measurement scales. Health Qual Life Outcomes. 2011;9(1):8.

16. Friborg $\mathrm{O}, \mathrm{Hjemdal} O$. Resilience as a measure of adaptive capacity. J Norwegian Psychol Assoc. 2004;41:206-8.

17. Friborg $\mathrm{O}$, Martinussen $\mathrm{M}$, Rosenvinge JH. Likert-based vs. semantic differential-based scorings of positive psychological constructs: a psychometric comparison of two versions of a scale measuring resilience. Personal Individ Differ. 2006:40(5):873-84.

18. Friborg $\mathrm{O}$, Hjemdal $\mathrm{O}$, Martinussen M, Rosenvinge JH. Empirical support for resilience as more than the counterpart and absence of vulnerability and symptoms of mental disorder. J Individ Differ. 2009;30(3):138-51.

19. Friborg $\mathrm{O}, \mathrm{Hjemdal} \mathrm{O}$, Rosenvinge $\mathrm{JH}$, Martinussen $\mathrm{M}$. A new rating scale for adult resilience: what are the central protective resources behind healthy adjustment? Int J Methods Psychiatr Res. 2003;12(2):65-76.

20. Friborg $\mathrm{O}, \mathrm{Hjemdal} \mathrm{O}$, Rosenvinge $\mathrm{JH}$, Martinussen M, Aslaksen PM, Flaten MA. Resilience as a moderator of pain and stress. J Psychosom Res. 2006:61(2):213-9.

21. Hjemdal O, Friborg O, Stiles TC, Rosenvinge JH, Martinussen M. Resilience predicting psychiatric symptoms: a prospective study of protective factors and their role in adjustment to stressful life events. Clin Psychol Psychotherapy. 2006;13(3):194-201.

22. Hjemdal O, Friborg O, Stiles TC. Resilience is a good predictor of hopelessness even after accounting for stressful life events, mood and personality (NEO-PI-R). Scand J Psychol. 2012;53(2):174-80.

23. Morote R, Hjemdal O, Uribe PM, Corveleyn J. Psychometric properties of the resilience scale for adults (RSA) and its relationship with life-stress, anxiety and depression in a Hispanic Latin-American community sample. PLoS One. 2017;12(11):e0187954.

24. Anyan F, Hjemdal O, Bizumic B, Friborg O. Measuring resilience across Australia and Norway: validation and psychometric properties of the English version of the resilience scale for adults. Eur J Psychol Assess. 2019. https://doi.org/10.1027/1015-5759/a000509.

25. Hirani SS, Lasiuk G, Van Vliet KJ, Van Zanten SV, Karmaliani R, Norris CM. Comparison of Urdu versions of the resilience scale and the resilience scale for adults. J Nurs Meas. 2018;26(1):106-20.

26. Narayanan A. The resilient individual: a personality analysis. J Indian Acad Applied Psychol. 2008;34:110-8

27. Jowkar B, Friborg O, Hjemdal O. Cross-cultural validation of the resilience scale for adults (RSA) in Iran. Scand J Psychol. 2010;51(5):418-25. 
28. Hjemdal O, Vogel PA, Solem S, Hagen K, Stiles TC. The relationship between resilience and levels of anxiety, depression, and obsessivecompulsive symptoms in adolescents. Clin Psychol Psychotherapy. 2011;18(4):314-21.

29. Hjemdal O, Roazzi A, Maria da Graça B, Friborg O. The cross-cultural validity of the Resilience Scale for Adults: a comparison between Norway and Brazil. Bmc Psychology. 2015;3(1):18.

30. Hilbig J, Viliūnienè R, Friborg O, Pakalniškienè V, Danilevičiūtè V. Resilience in a reborn nation: validation of the Lithuanian resilience scale for adults (RSA). Compr Psychiatry. 2015;60:126-33.

31. Gerino E, Rollè L, Sechi C, Brustia P. Loneliness, resilience, mental health, and quality of life in old age: a structural equation model. Front Psychol. 2017:8:2003.

32. Zhao X, Zhang D, Wu M, Yang Y, Xie H, Li Y, et al. Loneliness and depression symptoms among the elderly in nursing homes: a moderated mediation model of resilience and social support. Psychiatry Res. 2018;268:143-51.

33. Perron JL, Cleverley K, Kidd SA. Resilience, loneliness, and psychological distress among homeless youth. Arch Psychiatr Nurs. 2014;28(4):226-9.

34. Pakdaman S, Saadat H, Shahyad S, Ahmadi K, Hosseinialhashemi M. The role of attachment styles and resilience on loneliness. Health Sciences. 2016:5(9):268-74.

35. Kidd S, Shahar G. Resilience in homeless youth: the key role of selfesteem. Am J Orthop. 2008;78(2):163-72.

36. Rew L, Thomas N, Horner SD, Resnick MD, Beuhring T. Correlates of recent suicide attempts in a triethnic group of adolescents. J Nurs Scholarsh. 2001;33(4):361-7.

37. Efrati-Virtzer M \& M. Margalit M.Students' behaviour difficulties, sense of coherence and adjustment at school: risk and protective factors, Eur J Special Needs Educ, 2009:24(1), 59-73,

38. Sharabi A, Levi U, Margalit M. Children's Loneliness, Sense of Coherence, Family Climate, and Hope: Developmental Risk and Protective Factors. J Psychol. 2012;146(1-2):61-83.

39. Hughes ME, Waite LJ, Hawkley LC, Cacioppo JT. A short scale for measuring loneliness in large surveys: results from two population-based studies. Res Aging. 2004;26(6):655-72.

40. Friborg O, Barlaug D, Martinussen M, Rosenvinge JH, Hjemdal O. Resilience in relation to personality and intelligence. Int J Methods Psychiatr Res. 2005;14(1):29-42.

41. Hjemdal O, Friborg O, Stiles TC, Martinussen M, Rosenvinge JH. A new scale for adolescent resilience: grasping the central protective resources behind healthy development. Meas Eval Couns Dev. 2006;39(2):84-96. https://doi.org/10.1080/07481756.2006.11909791.

42. Derogatis LR, Lipman RS, Rickels K, Uhlenhuth EH, Covi L. The Hopkins symptom checklist (HSCL): a self-report symptom inventory. Behav Sci. 1974;19(1):1-15.

43. Müller JM, Postert C, Beyer T, Furniss T, Achtergarde S. Comparison of eleven short versions of the symptom checklist 90-revised (SCL-90-R) for use in the assessment of general psychopathology. J Psychopathol Behav Assess. 2010;32(2):246-54.

44. Morote Rios R, Hjemdal O, Martinez Uribe P, Corveleyn J. Life stress as a determinant of emotional well-being: development and validation of a Spanish-language checklist of stressful life events. Health Psychol Behavioral Med. 2014;2(1):390-411.

45. Nettelbladt P, Hansson L, Stefansson C, Borgquist L, Nordström G. Test characteristics of the Hopkins symptom check List-25 (HSCL-25) in Sweden, using the present state examination (PSE-9) as a caseness criterion. Soc Psychiatry Psychiatr Epidemiol. 1993;28(3):130-3.

46. Kaaya SF, Fawzi MS, Mbwambo J, Lee B, Msamanga GI, Fawzi W. Validity of the Hopkins symptom Checklist-25 amongst HIV-positive pregnant women in Tanzania. Acta Psychiatr Scand. 2002;106(1):9-19.

47. Tinghög P, Carstensen J. Cross-cultural equivalence of HSCL-25 and WHO (ten) wellbeing index: findings from a population-based survey of immigrants and non-immigrants in Sweden. Community Ment Health J. 2010;46(1):65-76.
48. Ventevogel P, De Vries G, Scholte WF, Shinwari NR, Faiz H, Nassery R, et al. Properties of the Hopkins symptom Checklist-25 (HSCL-25) and the self-reporting questionnaire (SRQ-20) as screening instruments used in primary care in Afghanistan. Soc Psychiatry Psychiatr Epidemiol. 2007:42(4):328-35.

49. Antonovsky A. Helbredets mysterium: at tåle stress og forblive rask. Lev, A., translator. København: Hans Reitzel; 2000.

50. Kimhi S, Eshel Y. The missing link in resilience research. Psychol Inq. 2015;26(2):181-6.

51. Eriksson M, Lindstrom B. Antonovsky's sense of coherence scale and the relation with health: a systematic review. J Epidemiol Community Health. 2006;60(5):376-81.

52. Torsheim T, Aaroe LE, Wold B. Sense of coherence and school-related stress as predictors of subjective health complaints in early adolescence: interactive, indirect or direct relationships? Soc Sci Med. 2001;53(5):603-14.

53. Hansen AØ, Kristensen HK, Cederlund R, Tromborg H. Test-retest reliability of Antonovsky's 13-item sense of coherence scale in patients with hand-related disorders. Disabil Rehabil. 2017;39(20):2105-11.

54. Muthén L, Muthén B. Mplus. The comprehensive modelling program for applied researchers: user's guide. Los Angeles: Muthén \& Muthén; 2016.

55. Bentler PM. Comparative fit indexes in structural models. Psychol Bull. 1990;107(2):238.

56. Marsh HW, Hau K, Wen Z. In search of golden rules: comment on hypothesis-testing approaches to setting cutoff values for fit indexes and dangers in overgeneralizing Hu and Bentler's (1999) findings. Struct Equ Model. 2004;11(3):320-41.

57. Browne MW, Cudeck R, Bollen KA, Long JS. Testing structural equation models. Thousand Oaks: Sage Publications; 1993.

58. Hu L, Bentler PM. Cutoff criteria for fit indexes in covariance structure analysis: conventional criteria versus new alternatives. Struct Equ Model Multidiscip J. 1999;6(1):1-55.

59. Perlman D, Peplau LA. Loneliness research: A survey of empirical findings. In: Peplau LA, Goldston SE, editors. Preventing the harmful consequences of severe and persistent loneliness. Rockville: National Institute of Mental Health; 1989. p. 13-46.

60. Windle G. What is resilience? A review and concept analysis. Rev Clin Gerontol. 2011;21(2):152-69.

61. Ungar, M. Pathways to resilience among children in Child Welfare, Corrections, Mental Health and Educational settings: navigation and negotiation. Child Youth Care Forum. 2005;34(6):423-44. https://doi.org/10.1007/ s10566-005-7755-7.

62. Wister A, Cosco T, Mitchell B, Fyffe I. Health behaviors and multimorbidity resilience among older adults using the Canadian longitudinal study on aging. Int Psychogeriatr. 2020;32(1):119-33. https://doi.org/10.1017/ S104161021900048.

63. Vanhalst J, Klimstra TA, Luyckx K, Scholte RH, Engels RC, Goossens L. The interplay of loneliness and depressive symptoms across adolescence: exploring the role of personality traits. J Youth Adolescence. 2012;41(6):776-87.

64. Maes M, Nelemans SA, Danneel S, Fernández-Castilla B, Van den Noortgate W, Goossens L, et al. Loneliness and social anxiety across childhood and adolescence: Multilevel meta-analyses of cross-sectional and longitudinal associations. Developmental Psychology. 2019;55(7):1548-65. https ://doi.org/10.1037/dev0000719.

65. Antonovsky A. Health, Stress and Coping.1979 Jossey-bass, San Francisco.

66. Bauer, G.F. et al. Future directions for the concept of salutogenesis: a position article. Health Promotion International, 2019, 1-9 perspectives. Oxford.

\section{Publisher's Note}

Springer Nature remains neutral with regard to jurisdictional claims in published maps and institutional affiliations. 